\title{
Knocking on Industry's Door: Needs in Product-Cost Optimization in the Early Product Life Cycle Stages
}

\author{
Matthias Walter ${ }^{*}$, Christian Leyh, and Susanne Strahringer \\ Chair of Information Systems, esp. IS in Manufacturing and Commerce \\ Technische Universität Dresden, 01062 Dresden, Germany \\ matthias.walter3@tu-dresden.de, christian.leyh@tu-dresden.de, \\ susanne.strahringer@tu-dresden.de
}

\begin{abstract}
While theoretical concepts for product-costing methodologies have evolved over the decades, little emphasis has been placed on their integration into modern information systems. During a co-innovation workshop at SAP SE, we initiated our collaborative research with selected large-scale enterprises from the discrete manufacturing industry. Moreover, we conducted interviews with business experts to gain a sophisticated understanding of the cost-optimization process itself. As a result, we present an exemplary optimization process with an emphasis on the specific characteristics of the product development stage. Based upon this example, we identified associated deficits in information system support. No current software fulfills the enterprises' requirements regarding cost optimization in the early stages of a product's life cycle. Thus, the respective processes lack integration in corporate environments. Taking this on, our article compiles detailed problem identification and, moreover, suggests approaches to overcome these hurdles.
\end{abstract}

Keywords: Product costing, product-cost optimization, product development, enterprise systems, product life cycle, process optimization.

\section{Introduction}

Besides agility, innovation, and quality, the optimization of costs has become a driver for longlasting economic success. This is especially important for industries such as the process industry or discrete manufacturing industry, as production requires capital-intensive assets and markets are highly competitive; thus, cost effectiveness is a major driver of success [1]. In such an economic environment, it is essential to have a clear overview of product costs. Therefore, product costing aims to analyze such costs across product portfolios. As part of managerial accounting, product costing determines the total costs per unit of production (or unit of service delivered) by analyzing what resources are being used in what ways. For instance, product

* Corresponding author

(C) 2017 Matthias Walter et al. This is an open access article licensed under the Creative Commons Attribution License (http://creativecommons.org/licenses/by/4.0).

Reference: M. Walter, C. Leyh, and S. Strahringer, "Knocking on Industry's Door: Needs in Product-Cost Optimization in the Early Product Life Cycle Stages," Complex Systems Informatics and Modeling Quarterly, CSIMQ, no. 13, pp. 43-60, 2017. Available: https://doi.org/10.7250/csimq.2017-13.03

Additional information. Author's ORCID iD:, S. Strahringer - orcid.org/0000-0002-9465-9679. Article PII S225599221700076X. Article received: 2017 September 30. Accepted: 2017 December 22. Available online: 2017 December 29. 
costing supports the operating manufacturing process, steers budgeting and investments, and significantly supports strategic decisions to shape a future product portfolio by estimating a product's future costs during product development [2], [3].

The necessity to efficiently calculate costs with high accuracy has led to the development of advanced methodologies for product costing. While a multitude of applications for existing costing concepts have been continuously broadened (e.g., time-driven activity-based costing [4], [5], [6], [7]), at the same time, their degree of specialization has increased (e.g., dedicated methodologies for woodworking [8] or welding [9]). As a result of such methodological diversity, recent research even addresses the selection of appropriate concepts within specific contexts [10].

In contrast to the variety of methodology available, only scant emphasis within the broad area of product costing is placed on its integration with modern information technology or information systems [11]. This is even more surprising as enterprises and everyday life become more and more digitized. Digging deeper into the topic of product costing, ERP systems are positioned as cornerstones for the digital support of product costing, as they provide functionality to collect and analyze the costs of various business functions across each enterprise [12]. Such functions are part of actual costing processes that analyze the present flow of resources within an enterprise, and thereby provide information about incurred costs in relation to accounting periods [13]. Such an accounting period marks only a fraction of the product's total life cycle (Figure 1). This is the case especially for the discrete manufacturing industry that produces automobiles, agricultural machines, or complex industrial machines. Because these products are assembled from thousands of globally sourced components, they require distinct development, testing, and planning efforts. In particular, the product development phase includes an innovation phase, during which products are conceptualized and designed, various research and development activities are conducted, product tests are performed, and plans for the upcoming production are devised [14].

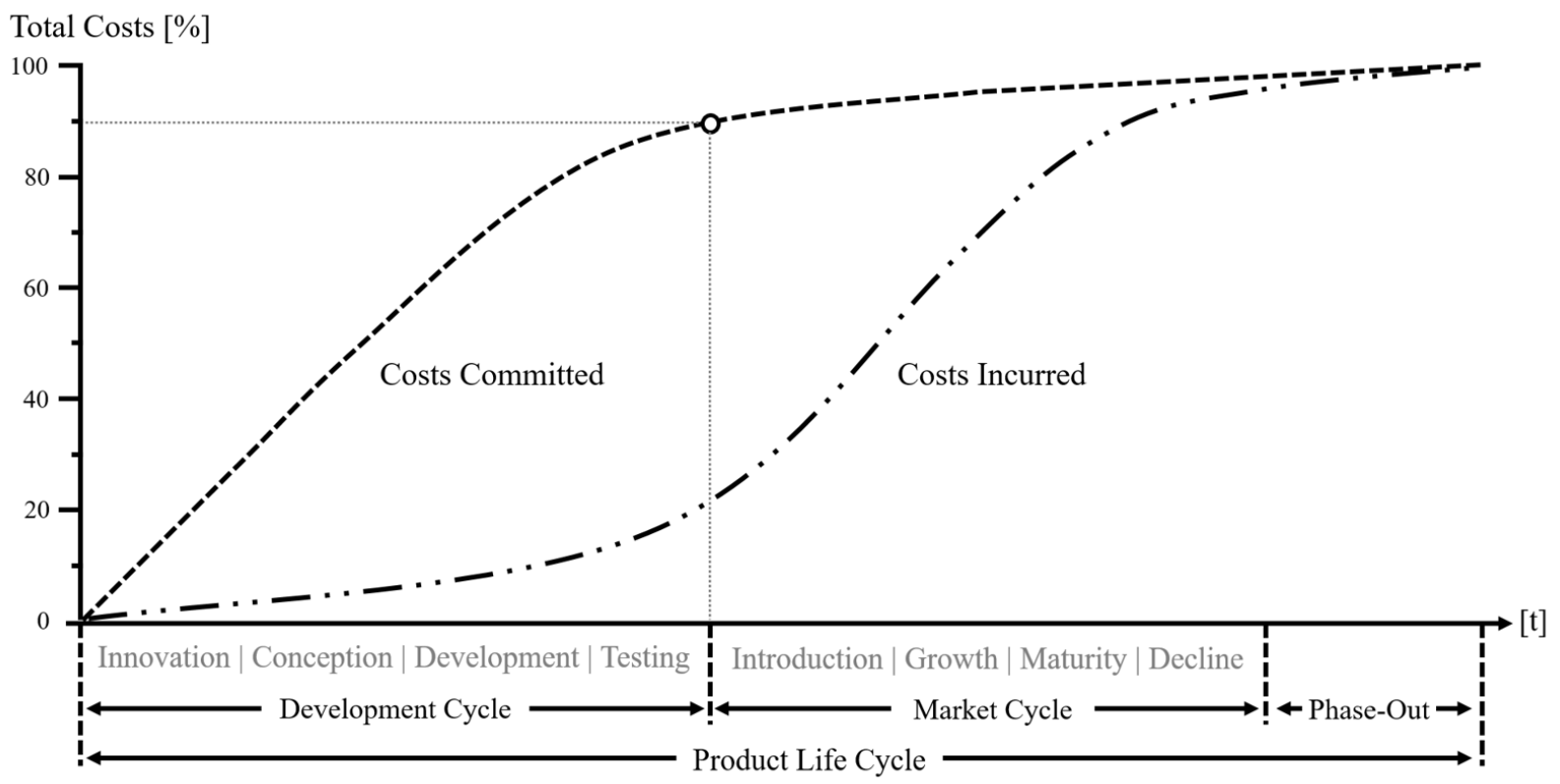

Figure 1. Cost commitment along the product life cycle [15]

When it comes to incurred costs, product development is responsible for only $20 \%$ of total product costs along the product's life cycle (Figure 1). When looking more closely into the cost situation, up to $90 \%$ of total products costs are being finally committed to by the end of the development phase and, therefore, before their production has even started [13]. This is crucial for driving cost optimization as this optimization cannot be performed with the incurrence of costs, but has to be completed during product development. Because the vast majority of 
information systems (such as ERP systems) address the analysis of incurred costs, they are not designed to support early product costing and its optimization [16], [17]. Therefore, during the product development cycle, product costing and its optimization lack information system support, especially from a practitioner's perspective.

To validate these assumptions we conducted a study to gain insights into the status quo of early product-cost optimization, focusing on cost-optimization processes in relation to their information system support during product development. Because this contribution serves as the problem-centered initiation of our long-term design science research project [18], [19], it is necessary to ensure both practical relevance and scientific rigor [20]. Therefore, we follow a collaborative research approach with international business experts specializing in product development in the discrete manufacturing industry, as recommended by Österle and Otto [21]. In addition to our previous problem identification [15], we had the opportunity to involve additional domain experts from the discrete manufacturing industry. Besides interviews, we consulted focus groups to verify previous results on challenges regarding early cost optimization and to frame a more detailed picture of industry's status quo. Moreover, we conducted a process and requirements analysis designed to foster our problem identification of deficient IT support in product costing. This problem identification is intended to serve as a valid foundation for our further research activities. Regarding our first studies, we aim to answer the following research questions:

Q1: How is early product-cost optimization conducted in the discrete manufacturing industry from a process perspective?

Q2: What are the major characteristics of product-cost optimization within the context of product development?

Q3: Which information systems are currently used to support early product-cost optimization, and which deficits can be revealed within this status quo?

To answer these questions, the following section provides research background on our problem identification. We then introduce our research methodology in Section 3. In Section 4 our findings are presented. Complementary to previous work [15], we describe an example process of early product-cost optimization followed by an industry-specific evaluation of optimization measures applied within the discrete manufacturing industry. Moreover, we highlight the main characteristics of the early product-cost optimization process and its deficits. The article concludes with a discussion of the identified problems' relevance and drafts a problem classification in combination with a recommendation for a promising research approach to finally improve information system support in this area.

\section{Background}

As noted in the previous section, product costing is used to evaluate products from a financial perspective. Only dedicated product-costing methodologies supported by the appropriate IT enable manufacturers to evaluate costs in a manner that fulfills business requirements [22]. Managing sourcing decisions, estimating sales prices, or adjusting product designs to fit market prices are only a few decisive fields that benefit from product-costing efforts within the productdevelopment phase. Overall, the objective is to remain competitive by estimating costs as precisely as possible to ensure that future sales will cover these costs [23].

Because of this, product costing had to be, and has been, adapted as well. Examining the use of product costing in regard to time, costing was mainly intended to support internal functions, such as purchasing, production, and sales, by analyzing the direct costs incurred [24]. The rapidly increasing dynamism of markets in interference with global networks has led to a shortage of innovation and product life cycles as product portfolios continuously diversify. This requires greater flexibility with regard to production level and leads to a higher amount of 
indirect costs not directly accountable to products [25]. Such a transformation impacts product costs not only by raising indirect costs up to $80 \%$ [26] but also by committing total product costs along the entire life cycle to a degree of at least $70 \%$ [27] and up to $90 \%$ by the end of the product-development phase [13]. These numbers indicate that the product-costing methodologies that have been used for decades, which evaluate only the present flow of values, are inheriting disadvantages that no longer fit today's requirements (e.g., because of stressing direct costs as a major source driving cost optimization [28], not supporting cost-effective product design decisions [29], or not evaluating relationships across the product portfolio [23]).

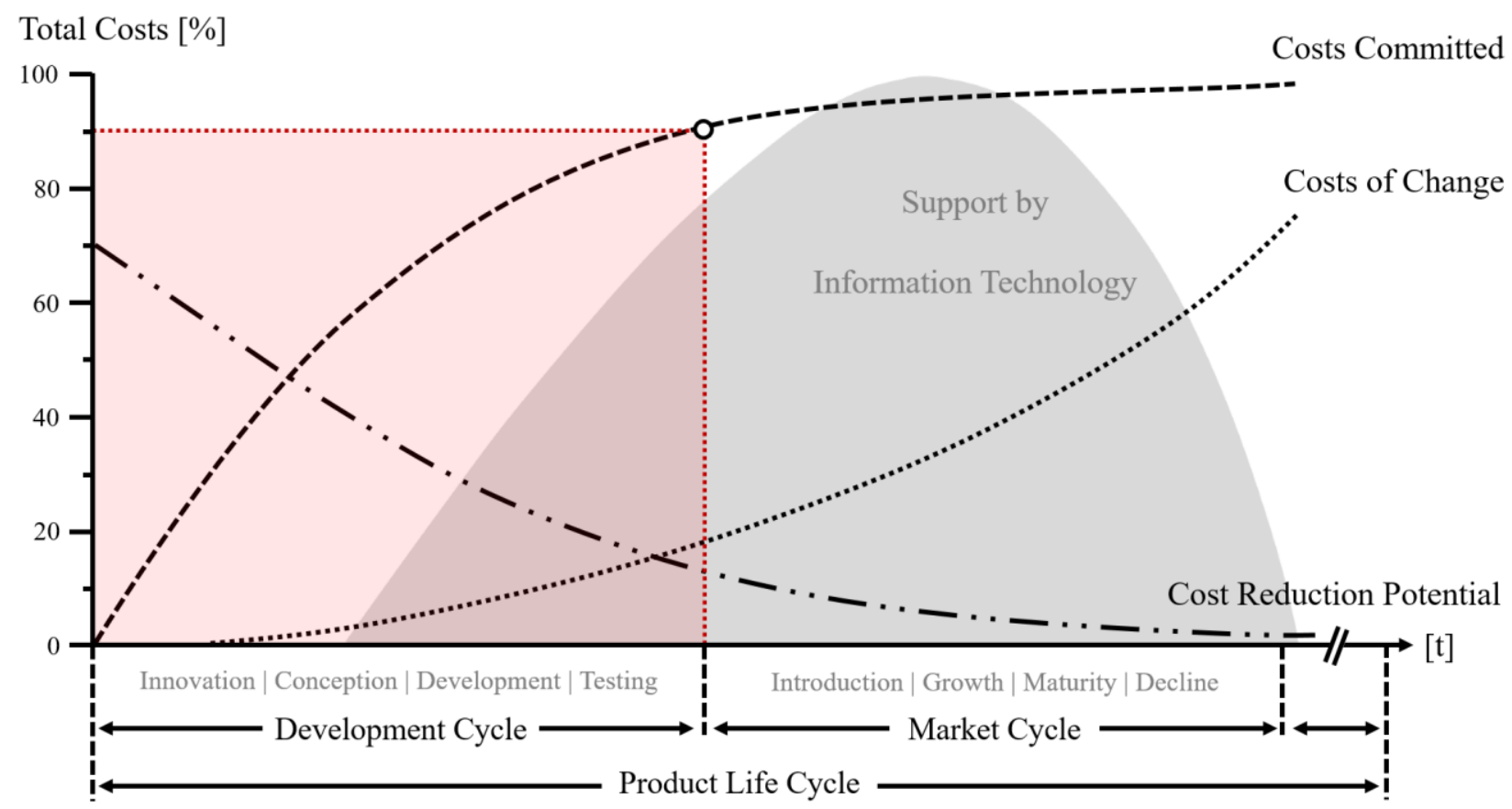

Figure 2. Cost commitments and reduction potential along product life cycle ([15], adapted from [30])

Alternative costing methodologies, such as life-cycle costing (LCC), have long been available in theory to overcome such drawbacks. In addition, authors such as Horváth [31] stress that product-cost optimization has to shift from being a working area for operative functions, such as production and purchasing, to being an activity that takes place within product development. Only then can better decisions be made that avoid costly and time-consuming changes in later life cycle stages (Figure 2). However, as stated by Schicker et al. in 2008 [27] and Stark in 2015 [16], software support for costing methodologies that addresses the requirements of productdevelopment phases was not available to the same degree as it is today through off-the-shelf or packaged software for actual costing and, therefore, was mainly dominated by spreadsheet solutions. Although meeting flexibility requirements, the spreadsheet approach implies pitfalls such as high workloads due to manual data maintenance, increased error rates due to inconsistencies across simultaneous modified versions, missing domain-specific functionality, and lack of transparency [27]. This gap between the variety of methodologies and limited software support becomes even more interesting for our research, as Schicker et al. [27] concluded in their study years ago, highlighting the need to find intelligent IT solutions that support product-cost optimization before the start of production. They considered these solutions as an indispensable prerequisite for effective future product costing. Thus, this article also evaluates tool usage across the discrete manufacturing industry to gain insight into the progress (or lack of progress) that has been made in terms of software support since 2008. Analyzing this, we also aim to reveal additional process characteristics and deficits that have thus far remained hidden. 


\section{Methodology}

The major purpose of this article is to elaborate a problem-centered initiation for our long-term design science research project concerning information system support for cost optimization during product development. We consider this as the first step in deliberately formulating our research problem, as suggested in Nielsson et al. [32], within the research approach proposed by Peffers et al. [19]. To ensure the problem's relevance as argued in Rosemann et al. [33], and therefore validate earlier research results concerning a lack of information system support (see Section 2), it is necessary to consider industry's state of the art in parallel to a scientific perspective [21]. In addition, current research [34] identifies industrial practice as the most important source for learning about cost reduction projects. For further industry collaboration we consider discrete manufacturing as a research reference due to its 1) distinct product development cycles and 2) demand for cost-effective product development [1].

The first objective is to gain a sophisticated understanding of the cost-optimization process itself and to substantiate the associated problems to address them in the future. Because product costing includes a long history of methodologies relying on expert knowledge (e.g., analogous models [35]), and, in particular, because product development is a knowledge-intensive process [36], we chose to rely on well-established methods in the context of design science research to capture tacit knowledge [21].

Therefore, we initiated our collaborative research by joining a co-innovation session at SAP SE, where potential and current SAP customers discuss business concepts and software requirements for the development of a new software for product life-cycle costing framed by an agile development process [37]. We conducted a workshop with 19 dedicated business experts from 6 international operating companies of the automotive and machine-construction sectors (both as parts of the discrete manufacturing industry). These experts had different roles and responsibilities in their respective companies (Table 1), including product costing, product engineering, information technology, and management. Due to their highly complex roles within the organizations and, thus, also within product-cost optimization, in the first study we focused only on experts from large-scale companies (those with more than 3,000 employees). Those enterprises are characterized not only by high product complexity (in the discrete manufacturing industry) but also by an inherent organizational complexity (a variety of roles and functions, nested supply chains, etc.), which is suitable for the formulation of accurate problem statements and avoiding oversimplification.

Table 1. Overview of study participants in relation to their areas of competence (study 1)

\begin{tabular}{|l|c|}
\hline \multicolumn{1}{|c|}{ Area of Competence } & Participants \\
\hline Product controlling & 8 \\
\hline Project controlling & 5 \\
\hline Product engineering & 1 \\
\hline Product management & 1 \\
\hline Information technology & 4 \\
\hline Overall & 19 \\
\hline
\end{tabular}

To structure the initial workshop session, in the first run we asked only dedicated product and project controllers (also referred to as "costing experts") to present their current processes of product-cost optimization within product-development phases. To prevent participants from influencing one another, they were asked to prepare the information sessions independently, guided by these initial questions:

1. How, when, and why do you optimize product costs?

2. What problems do you face when optimizing product costs (especially related to software support)? 
3. Where and to what end do you need better software support?

After the results were presented to the group of costing experts, we arranged the significant outcomes into a common summary. To gain more detailed insights into the process and its complexity from different perspectives, in the second run we subsequently validated the outcome with experts in different roles and with varying responsibilities. Therefore, the common summary of the first run was presented to the entire group of 19 experts. At this point, experts from product engineering, information technology, and management were able to highlight, modify, or enrich important information from their own perspectives. In this way, we collected further details about the collaboration required for optimizing this process as well as about software solutions currently used and their degree of integration. In total, this resulted in an overall picture of early product-cost optimization that frames our long-term further research activities.

We then conducted a second study to deepen our understanding of the industry's needs. The second study followed up on the results of our initial workshop session, which served as access to our research environment [18]. To approach the detailed extraction of practitioner knowledge, we individually interviewed experts within the discrete manufacturing industry [21]. The interview results were then evaluated by a focus group of industry experts as part of a later coinnovation session at SAP SE. With regard to the extraction of process knowledge, it was necessary to examine an industry example and refine how product-cost optimization is typically conducted in the early life cycle phases. Therefore, we combined design-oriented research techniques [21] into a line of actions as follows:

1. Interviews with industry domain experts,

2. Analysis of interviews,

3. Elaboration of an optimization process,

4. Optimization process evaluation by domain experts.

As the first step of the second study, we conducted 11 interviews with international business domain experts who came from different industries and possessed different competences (Table 2). Those structured interviews were aimed at a process understanding of early product-cost optimization and its characteristics of execution.

Table 2. Expert interviews (step 1): industry and competence distribution of participants (study 2)

\begin{tabular}{|l|c|}
\hline \multicolumn{1}{|c|}{ Industry } & Participants \\
\hline Automotive & 7 \\
\hline Machinery construction & 3 \\
\hline Food & 1 \\
\hline Overall & 11 \\
\hline
\end{tabular}

\begin{tabular}{|l|c|}
\hline \multicolumn{1}{|c|}{ Area of Competence } & Participants \\
\hline Product controlling & 7 \\
\hline Product engineering & 1 \\
\hline Consulting & 2 \\
\hline Information technology & 1 \\
\hline Overall & 11 \\
\hline
\end{tabular}

We analyzed these interviews to elaborate an aligned optimization process that could serve as a future reference point for aligning our research objectives. Furthermore, the elaboration was designed to identify common implementation challenges for information system support for early product-cost optimization within the discrete manufacturing industry [38]. In the final step of our second study, we presented the results to a focus group of business experts (Table 3) at an additional co-innovation workshop at SAP SE. With only two overlapping participants in the group of expert interviewees, 18 participants from different industries and with different roles (Table 3) evaluated our interview outcomes. To support our research results, we iterated through single characteristics of the elaborated model of a cost-optimization process. To broaden the evaluation and ensure we captured different perspectives among process stakeholders regarding industries (Table 3), areas of competence, and working experiences (Table 4), each focus group participant was asked to rate those characteristics individually with a score from 0 to 10 . 
Table 3. Evaluation (step 4): industry distribution of participants (study 2)

\begin{tabular}{|l|c|c|c|}
\hline \multicolumn{1}{|c|}{ Industry } & Participants & $\begin{array}{c}\text { Average Work } \\
\text { Experience }\end{array}$ & $\begin{array}{c}\text { Median Work } \\
\text { Experience }\end{array}$ \\
\hline Automotive & 12 & 9.6 years & 6.0 years \\
\hline Machinery construction & 4 & 3.5 years & 3.5 years \\
\hline Consulting & 2 & 4.5 years & 4.5 years \\
\hline Overall & 18 & 8.0 years & 5.0 years \\
\hline
\end{tabular}

Table 4. Evaluation (step 4): Competence distribution of participants (study 2)

\begin{tabular}{|l|c|c|c|}
\hline \multicolumn{1}{|c|}{ Industry } & Participants & $\begin{array}{c}\text { Average Work } \\
\text { Experience }\end{array}$ & $\begin{array}{c}\text { Median Work } \\
\text { Experience }\end{array}$ \\
\hline Product controlling & 10 & 9.6 years & 8.5 years \\
\hline Product engineering & 1 & 6.0 years & 6.0 years \\
\hline Consulting & 2 & 4.5 years & 4.5 years \\
\hline Information technology & 5 & 6.0 years & 6.0 years \\
\hline Overall & 18 & 8.0 years & 5.0 years \\
\hline
\end{tabular}

\section{Findings}

In the Findings section, we begin with results from the second study, as they are useful for illustration and give deeper insight into the investigated domain. Thus, an example of early product-cost optimization for the discrete manufacturing industry is used to highlight major process characteristics.

\subsection{Status Quo: Industry Example for Early Cost Optimization}

To answer the first research question and ensure a common understanding of the problem domain and its characteristics, this section depicts early product-cost optimization in an exemplary way with the evaluated research results from our second study. For this purpose, we chose the development of a modern car within the automobile industry. Depending on the vehicle model and the leap in development compared to a model's predecessor, the development project can last for up to 5 years [39], [15]. This product development cycle is structured into several dedicated phases (e.g., conceptualization, development, and testing).

Nonetheless, product development is not a stringent process [36]. This classification is especially true for product-cost optimization during this phase, which aims at finding the most beneficial solutions in a certain context. To do so, so-called "costing workshops" are held on a regular basis during product development. Stakeholders from controlling, engineering, purchasing, product management, and sales participate in these workshops to discuss the current state of the product, brainstorm ideas for product-cost improvements, and review progressed cost optimization measures. Their ideas for improvement can be aggregated into categories of optimization measures, which have been evaluated by the participants of the second study as stated in Table 5.

In the context of the development of a new automobile or automobile parts, make-or-buy analysis play a significant role (Table 5). For a car manufacturer, the outcome of a costing workshop could be, for instance, that the controlling department must perform a make-or-buy 
analysis to evaluate whether a specific component like a turbocharger can be better sourced. Actions to be taken are collected in an aggregated list containing the entirety of ideas for improvements, such as potential optimization measures. Secondly, responsibilities for such potential measures are defined. Due to highly interdisciplinary activities, responsibilities (such as specific departments within the organization and responsible task owners) must be distinctly assigned to each potential optimization measure. This ensures clear organizational responsibilities for the optimization process [15]. At the same time, the achievement plan for each optimization measure is scheduled with respect to the different stages of the product development cycles.

Table 5. Evaluated optimization measures

\begin{tabular}{|l|c|c|c|c|}
\hline \multirow{2}{*}{\multicolumn{1}{|c|}{ Optimization Measures }} & \multicolumn{3}{|c|}{ Average Score } & Std. Dev. \\
\cline { 2 - 5 } & Overall & Automotive & $\begin{array}{c}\text { Machinery } \\
\text { Construction }\end{array}$ & Overall \\
\hline Alternative concept and product designs & 7.33 & 7.75 & 7.50 & 1.89 \\
\hline $\begin{array}{l}\text { Alternative reference components, } \\
\text { assemblies, materials, and recipe ingredients }\end{array}$ & 7.06 & 7.00 & 7.00 & 2.66 \\
\hline Alternative production plants & 7.29 & 7.82 & 7.75 & 2.37 \\
\hline $\begin{array}{l}\text { Alternative production processes and } \\
\text { production process optimizations }\end{array}$ & 6.56 & 7.08 & 4.50 & 2.36 \\
\hline Lot size and cycle time optimizations & 4.88 & 5.80 & 1.75 & 2.74 \\
\hline Material price optimization & 7.78 & 8.25 & 7.25 & 2.10 \\
\hline Make-or-buy decisions & 7.83 & 7.92 & 8.25 & 1.57 \\
\hline Investments in tools or equipment & 5.88 & 7.73 & 2.50 & 3.01 \\
\hline Optimization of logistics costs & 5.61 & 6.58 & 4.25 & 2.69 \\
\hline
\end{tabular}

Parallel to the ongoing product development, each measure is further evaluated. After an estimation of potential impacts or boundary conditions like target costs, the identification of possible solutions continues. To identify opportunities for the make-or-buy of a turbocharger, different suppliers are asked for quotations to draft different concepts on how to perform the optimization measure; at the same time, in-house production opportunities are determined.

After significant alternatives have been arranged, they are evaluated and compared using financial figures, such as costs per piece, total costs, RoS (return on sales), RoCE (return on capital employed), and IRR (internal rate of return) to identify the most beneficial option for the upcoming implementation of an optimization measure. Besides financial interests, strategic aspects can influence the final decision on a suitable alternative (e.g., capacity utilization for a specific plant).

The final decision to implement an optimization measure marks an important milestone for a measure's maturity. As soon as it reaches this significant maturity level, the measure fulfills all requirements to enhance the product under development. Therefore, necessary actions such as changing the product design, adjusting production processes, or making material procurements are initiated to finalize the optimization process for a specific measure.

\subsection{Process Characteristics}

Based on the previous section outlining an exemplary optimization process, this section answers the second research question by selectively highlighting important characteristics of the early cost-optimization process. These characteristics were outlined by industry experts during the workshop session of our first study (see Section 3). In general, cost optimization during the product-development phase is very much about estimating future costs. While estimations can never predict the exact real future costs, manufacturers strongly rely on costing estimations. 
They determine production feasibility, prepare investment decisions for new production equipment, and begin to steer resource allocations along procurement or production planning.

But how much are those issues estimated by the industry sector we address? Here, the product development phase is often intended to last up to 5 years (see Section 4.1), due to extended research efforts. In addition, regular market cycles continue for around 7 years. Instead of ending production with the end of a market cycle, automotive suppliers and automobile manufacturers guarantee spare part supplies for another 20 to 40 years after regular production has ended. Adding these figures up, product life cycles span 5 decades at most.

With this in mind, we discovered an organizational concern among experts: in many organizations, there is no iterative calculation process in place to systematically reconsider cost estimates or the estimated effects of optimization measures. Once classified as final, cost estimates remain untouched during the rest of the development cycle, which can last several years. The next available costing figure already results from actual costing methodologies and, therefore, reflects the cost situation after production has begun. This gap becomes critical for organizations, as early cost estimates are very often model-based expectations about prices and their future development during the market cycle (Figure 2). Although costing experts enrich those models according to their own experiences, only minor changes can influence profit margins and, as a result, the overall financial success of the product. For instance, enterprises consider the influence of politics as one of many unpredictable determinants; elections can easily influence the world's market prices for raw materials for a certain period of time. Such foreign influences will never be predictable. Nevertheless, when considering a product's life cycle in terms of decades, those influences should be considered within cost estimates as a subsequent adjustment during development cycles.

In addition, product-cost estimation is used to prepare quotations by considering cost estimates plus internal targets for profit margins. Described as a "call for tenders," customers ask manufacturers to provide offers for inquiries. Such initial inquiries within discrete manufacturing industry, including cost estimates for decades, can be asked for within lead times of only 2 business days. Furthermore, approximately $80 \%$ of all required resources (such as materials or processes) have neither been estimated nor produced within the organizations before, resulting in a high level of uncertainty about how to handle and optimize those materials. As a result, various suppliers spend a quarter of a year competing against one another in iterative tender processes. During this time, manufacturers have the opportunity to adjust their initial quotation, while at the same time, customers are guiding negotiations based on a should-cost analysis. Having signed a supply contract, sales prices are difficult to negotiate in case of a changed-cost situation.

Because the result of early product costing and its optimization was perceived by workshop participants as highly relevant for decision-making, the overall outcome of costing must be reliable. To date, however, cost estimates commonly suffer from a certain level of information uncertainty. One reason for this information uncertainty is unstructured and nonpersistent data. For instance, product designs can be easily changed to implement optimization measures (see Section 4.1) or fit evolved customer requirements. Automotive suppliers across all participating enterprises in particular have highlighted the customer's influence on the product design by predefining specific components to assemble. As a result, a product's bill of material can change to an extent where not only the selection of production plants must be reconsidered but also sourcing strategies must be analyzed from scratch. This ongoing product alteration during product-development requires a back-and-forth approach toward cost optimization that ensures various optimization potentials can be exploited at any point in time.

Usually, the study participants apply scenario techniques to overcome various hurdles. Driven by a best-case cost estimate, negative influence factors and risks are assessed (e.g., exchange-rate fluctuation). Once evaluated, potential effects are combined into different scenarios for future analysis. Nevertheless, with such scenario techniques in place, it is surprising that the processes designed to mitigate risks are not standardized within enterprises. Many risks, and therefore many optimization potentials as well as optimization approaches, lack perception. The workshop 
participants stated that the reason was as follows: instead of costing experts, it is primarily technical staff like product engineers who manage product-development projects within their organizations. The focus of such employees is to fulfill technical requirements and provide functionality, not to optimize costs. Thus, the relevance of cost optimization is perceived inadequately in comparison to its real potential for influencing future costs (Figure 2) and contributing to the organization's competitive edge.

Furthermore, optimization is not considered a high priority because optimization processes are neither standardized nor aligned within the organizations themselves. To drive optimization, costing experts must consider various tasks relying on their experience and knowledge. The vast majority of optimization tasks are currently performed manually. In addition, an optimization measure has to fulfill many criteria that each costing expert must implicitly evaluate. For instance, measures are analyzed based on their effects on financial performance indicators (see Section 4.1). In parallel, each optimization measure runs through a latent process describing various attributes like feasibility, its effect on financial figures, and its maturity in terms of integration with a cost estimate (in case alternative components are developed).

It is thus not surprising that organizations often skip an in-depth product-cost optimization due to the associated manual efforts and the high pressure to create quotations for customers. Costing and optimization processes are highly interdisciplinary, linking various functions within organizations such as accounting, engineering, purchasing, production planning, and sales. This communication across the organization leads to another aspect that has been frequently noted: rigid organizational structures that hinder integrated cost optimization. Cost optimization requires the strong interaction of different organizational areas (Figure 3). Functional objectives for different areas of responsibilities limit interaction and foster conflicts against optimization.

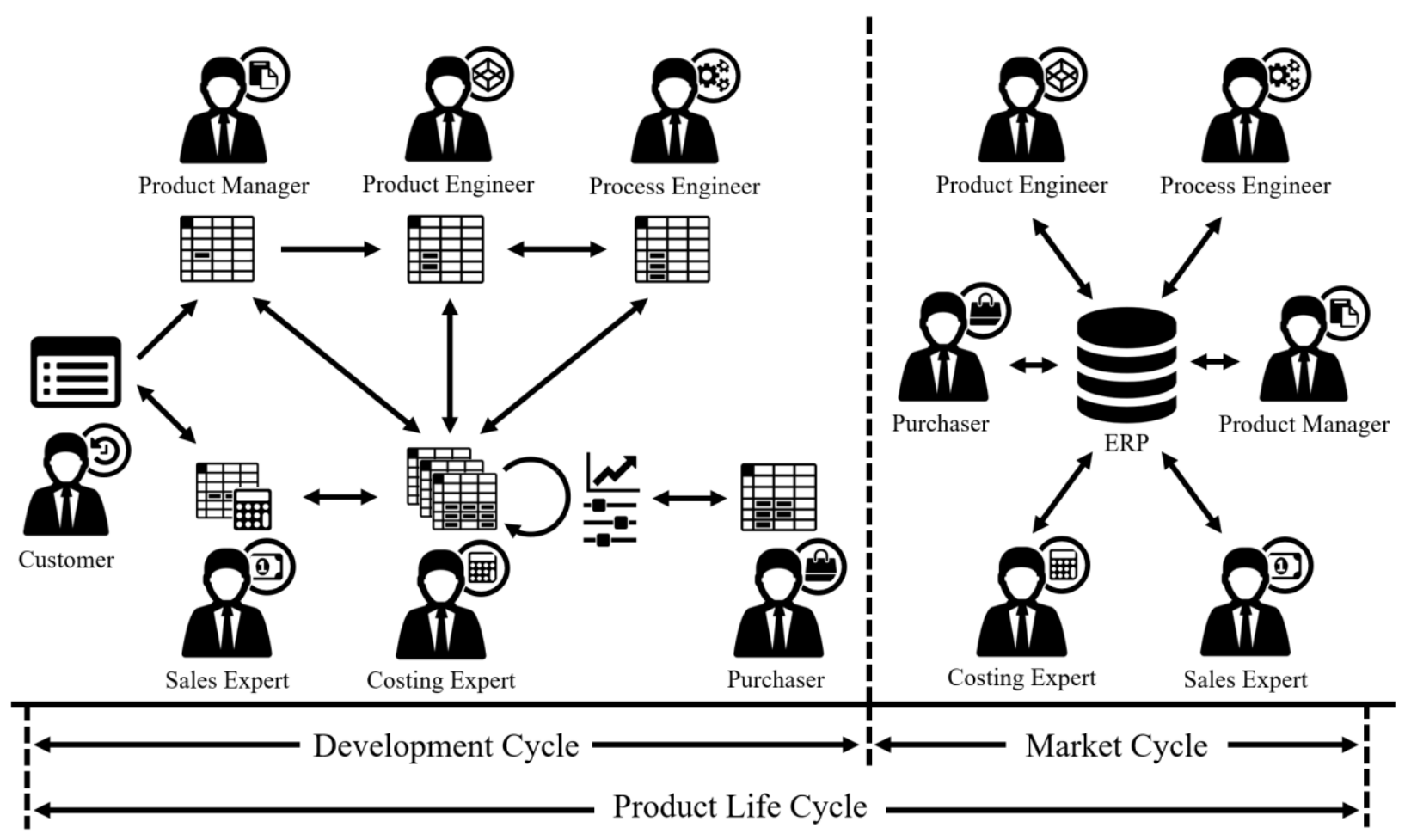

Figure 3. Software support within the development cycle in comparison to the market cycle [15]

In conclusion, product-cost optimization is a rather complex, loosely defined process based on several iterations. Furthermore, it requires a broad bandwidth of knowledge across each company and the industry as well. Particularly, costing experts have to ensure comprehensive expertise in regard to usage of materials in several contexts as well as decide on production methods and their impacts on future product costs. The importance of early product-cost optimization was well known to all study participants independent of their specific roles, industry, or position in the value chain; however, the actual process within the enterprises of the 
discrete manufacturing industry is still not perceived as expedient as the interviewed experts wanted it to be. Therefore, the next section will deal with findings regarding the process deficits and their association with the lack of appropriate software support.

\subsection{Status Quo: Deficits in Early Product-Cost Optimization Highlight a Strong Need for Improved IT Support}

Besides the explanation of process characteristics, we asked the participants of our first study to describe the interaction of their processes with information system support. The answer was rather unexpected: "There is no software support available to systematically leverage potentials of early cost optimization." The main tool used for costing and, therefore, cost optimization, identified by each workshop participant was the well-known spreadsheet application Microsoft Excel. Participants highlighted the flexibility of spreadsheet software as the primary reason for choosing it over the available costing software.

Yet, having Excel in place, participants complained about the manual processing of data. In particular, the missing functionality of monitoring features like change logs or a versioning system leads not only to inconsistency but also to an inability to trace magnitudes of impacts. This, again, results in loss of important knowledge across the organizations. Figure 3 highlights this disadvantage: process stakeholders work on data sets that are not centrally managed. In contrast to this, product costing activities during the market cycle (after SOP) are managed centrally in integrated systems like ERP systems. Without a dedicated single source of truth for early product costing data, these data lack integration with other systems. Such data integration is necessary to perform comparisons either within the different stages of product development or with actual costing results created in ERP systems.

Nevertheless, costing experts want to conduct a comparison to identify deviations between early estimates and actual calculations. Currently, they conduct it manually-once more using spreadsheet software with ERP exports included. Because of such manual efforts to run the analysis, deviations are not continuously tracked, even though analyzing deviations helps generate knowledge on optimizing costs from scratch. Some of the participating enterprises have created a database of this knowledge but have lost an overview of the collection as a whole because its manual data maintenance lacks a dedicated optimization process of checks. When it comes to the scenario techniques mentioned earlier, spreadsheets are the tool of choice as well. Costing experts determine potential optimization measures or negative impacts based on their business experience to improve cost-estimation accuracy.

Subsequently, experts manually evaluate financial effects for each optimization measure and their optimization alternatives (see Section 4.1) using spreadsheet workbooks including formulas and macros. In particular, costing data become inconsistent as soon as additional organizational areas like purchasing must be considered to perform optimization tasks (e.g., to ask for current material prices or alternative materials). Because a variety of employees from different departments work jointly on optimizations, there is currently no guarantee within a company's processes of keeping a full and consistent history of all optimization measures and influences on an early product-cost estimate (and its optimization). Only one participating organization has attempted to extend an existing costing software tool because of the organization's awareness of the disadvantages associated with spreadsheet software. Led by the idea of a centralized optimization measure catalog, users browse through a list of potential effects on a cost calculation for later evaluation. But this solution has the same disadvantages as the manual approach: neither are the effects on the current cost estimate calculated automatically, nor is the software able to evaluate and manage different versions as required for scenario techniques. Added to this, faulty access management leads to an excessive amount of duplicated optimization measures within the catalog, which overwhelms the experts. 


\subsection{The Expert Perspective: Fundamental Requirements to be Addressed}

To guide future research, we collected essential requirements to overcome current deficits (see Section 4.3). Therefore, participants in our first study nominated fundamental requirements. This section outlines those requirements and proposes a course of action for their implementation as a holistic approach in the problem domain.

As very first step, the ideal state of a software solution must be better vertically integrated with existing information systems such as ERP systems, where most master data are maintained. The use of multiple tools to perform product-cost calculations dependent on product life cycle phases is a weakness resulting in the many disadvantages already described and, therefore, requires horizontal integration as well.

Critical from a user's perspective was traceability. When working with spreadsheet software, all changes must explicitly be tracked manually. Because experts describe such manual operations as highly unreliable and inconsistent, we can see that traceability is very limited in enterprises' current setups. For instance, it is necessary to identify all the influences on a product's cost estimate (e.g., change of raw material prices). In addition, workshop participants demanded comparison features. On the one hand, this requirement is about comparing various cost estimates for one product along its life cycle to identify changes over time. By analyzing such changes, the reasons for changes and deviations are identified. Such reasons then generate knowledge on how to improve new estimates in terms of initial estimate accuracy (as initial reasons for changes have been considered already). On the other hand, comparisons across different products within one product group enable costing experts to conduct various crosschecks. For instance, it is important to compare cost proportions such as labor costs to one another. Once experts can identify such deviations (e.g., labor costs that are too high for single products), they have an opportunity to improve their estimates.

In a discussion of market prices, experts mentioned target costing as a strong field of interest. Familiar with a variety of different costing software solutions, experts agree on a lack of methodological support in comparison to theoretical availability. While product costing is designed to work bottom-up to calculate total costs, target costs is a top-down approach in which product costs are limited by providing a development budget or prices that represent the maximum costs of the final product [40]. Because products are assembled from many thousands of components, one top-level figure representing the target cost is not helpful for experts to drive cost optimization. What is required, instead, is a breakdown of specified target costs on various levels regarding the specific components. Such a schematic target-cost breakdown would allow enterprises to easily track deviations by comparing top-down breakdowns to bottom-up calculated costs level by level.

In addition to identifying fields of action for cost optimizations by target-cost-deviation tracking, current software solutions do not provide process guidance for applying optimization measures as described in Section 4.1. Once an idea for optimization is identified, it should be registered within a database. The measure can then be enhanced by attributes such as processing status, feasibility, or type of impacts. The software itself should automatically evaluate the various measures, so that identification of the most helpful actions can be conducted by experts. Moreover, various reporting capabilities should enhance integrated management across organizational functions. In particular, simulations dealing with different scenarios about factors of uncertainty should help identify important levers for optimization.

All in all, these requirements represent an expert's perspective of the current status quo. Figure 4 shows an aggregated collection of practitioners' requirements as an outline for an approach to overcome current deficits (see Section 4.3). This collection attempts to draft dependencies among the individual requirements. 


\section{Further Research}

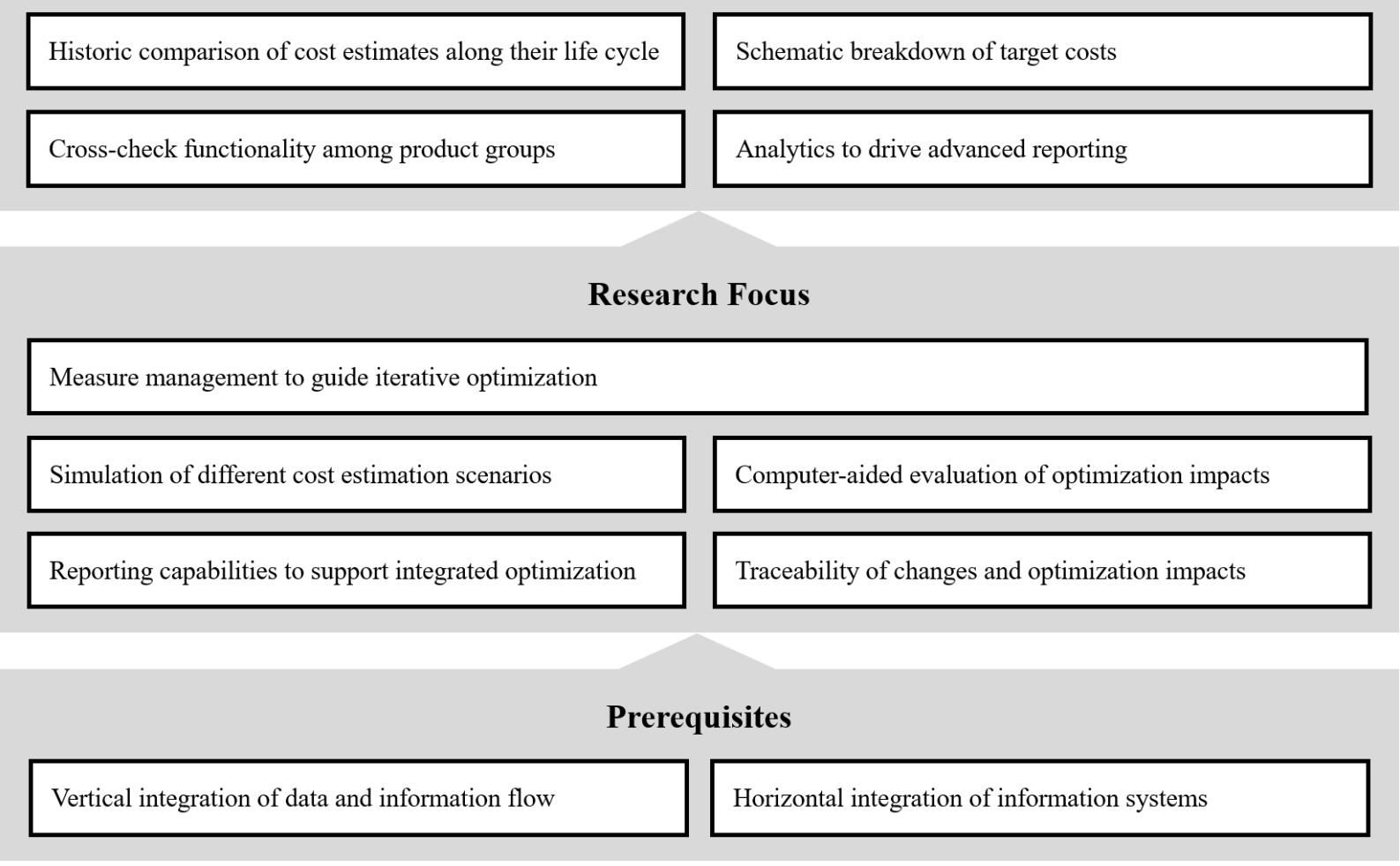

Figure 4. Software requirements for product-cost optimization within product development (adapted from [15])

While data integration is a perquisite to address advanced requirements in general, we intend to focus research activities in our long-term research project on information system support for knowledge-intensive process (see Section 3). Thus, the structured outline of Figure 4 serves as a foundation for our future elaboration of detailed requirements [38] and is discussed in the following section.

\section{Discussion}

Because enterprises and their costing experts are aware of the benefits of early product-cost optimization, it is surprising that spreadsheet software is a tool of choice and that organizations are willing to accept the many disadvantages that accompany this type of solution. With no major changes in the software solutions used by industry experts in nearly a decade, a question must be raised: is it reasonable from a scientific perspective to address the current problems and inappropriate software support associated with early product-cost optimization, or would doing so fail to provide any benefits worth capturing, because the future - and therefore future costs cannot be reliably predicted? To evaluate this question, Daschbach et al. [41] examined the consequences of cost estimations in the development cycle that deviate from product costs that occur during a product's market cycle. The consequences of underestimating costs are extensive.

By agreeing to sales prices that do not cover expenses, enterprises risk financial losses, or risk, at the least, encountering problems related to quality, just-in-time delivery, and more. Directly compared, cost overestimation appears to be less harmful than underestimation. However, in the context of the discrete manufacturing industry, overestimating costs can easily lead to the same outcome: due to competitive calls for tender processes, overestimated costs result in missing orders, which then become financial losses tied to a surplus of production capacities. Regardless of the direction in which estimates deviate, this raises serious business problems, hence the interest in continuously improving costing processes. 
As Section 4.4 reveals, several business requirements are still not supported by available costing softwares. In particular, the integration of costing software with industry's information systems constitutes an elementary requirement across the discrete manufacturing industry. In this context, Chang [42] highlights a point of interest. A lack of integrated costing software in existing environments seems to be a weakness for costing-related processes such as early cost optimization. Such integration is required as high data availability and quality are indispensable prerequisites for the application of modern costing methodologies, e.g. life cycle costing [43]. This is, once more, confirmed by our study. Aware of this deficit, Chang [42] proposes a CADbased costing solution integrated with product-design processes. Although real-time costing for engineers is a useful feature for performing cost-effective design, we had to learn that a technical background often leads to a conflict of priorities. Product design is very important, but engineers should not be forced to take on the roles of costing experts - nor vice versa - by an integration of generic costing functionality in dedicated engineering software.

Of essence here is the expertise of costing experts, especially considering product-cost estimates decades into the future. Keeping in mind the pressure of calls for tender processes described by our participants, a black-box optimization will not be accepted by organizations competing in those extensive processes. In the event of failure of software assumptions, product profitability can easily be ruined for decades. Therefore, it is necessary to provide domainspecific functionality to support costing experts. We referred earlier to Schicker et al. [27], who identified a lack of domain-specific functionality in 2008. In general, we underpin those results: the research domain continues to be dominated by spreadsheet software for nearly a decade, causing a broad bandwidth of deficits (see Section 4.3), and there is still no IS support available to fulfill the industry's requirements as seen from practitioners' responses. What should be challenged is the approach to improving IS for early product-cost optimization. Although we focused our collaborative research on the discrete manufacturing industry, there remains a diverse range to be noted in the evaluation of optimization measures (Table 5), depending on the specific industry sector. While there is a basic set of common optimization approaches valid for the discrete manufacturing industry, some aspects differ in relation to the type of production. Machinery construction has a strong focus on single-part production, whereby it does not benefit from economies of scale. In contrast, automotive companies focus on the optimization of recurring production-related activities (e.g., lot size optimizations, investment in tools, and the optimization of logistics costs). With this difference in mind, the overall approach to improving acceptance of IS within early product-cost optimization should not rely on the implementation of specific functionality or costing methodology (as existent in the literature, see Section 2) because it cannot satisfy the basic set of requirements across organizations.

Instead of implementing the bandwidth of product-cost optimization methodologies in IS, future research should focus on the guidance of the optimization process based on a common denominator. The challenge when aiming at a common process model is the industry's demand for flexibility. But how are we to address the most valuable requirement, namely flexibility, that spreadsheet software provides? Neither cost-estimating processes nor cost-optimization processes are standardized among the variety of companies that participated in both our studies. Furthermore, cost-optimization is a nonlinear process that does not align with structures of the product development cycle. Rather, early cost optimization is a knowledge-intensive approach driven by context-sensitive deliberations of relevant stakeholders (see Sections 4.1 and 4.3). In essence, neither participant stakeholders nor the scope of optimization measures are predictable in advance. Therefore, a highly flexible IS approach is required to support early cost optimization. The first indication on a functional and procedural level is described by Ehrlenspiel et al. [44]. The authors present a procedural cycle for cost reduction of products aiming at generality. Their approach underpins our understanding of how product-cost optimization works in industry (see Section 4.1).

Specifying the right degree of generality and, therefore, ensuring demanded flexibility is essential for defining further objectives for IS support. Markus et al. [36] argue for a new class of 
IS required to support a specific type of process, as there are processes in which neither the process itself nor the actor or the knowledge requirements are predictable. So-called "emergent knowledge processes" exhibit unique requirements causing major design problems. To solve these problems, it is necessary to agree on a common process model for cost optimization and further elaborate the degree of process specification [45].

To initiate such elaborations, we derived a processual perspective for early product-cost optimization (Figure 5) based on both study results. This proposal aims at the overall coordination of early product-cost optimization (Measure Management and Measure Reporting) as well as the specific process required to drive ideas for optimization measures (Identification) along with their evaluation (Evaluation and Decision) to their final implementation (Implementation) into the product (see Section 4.1).

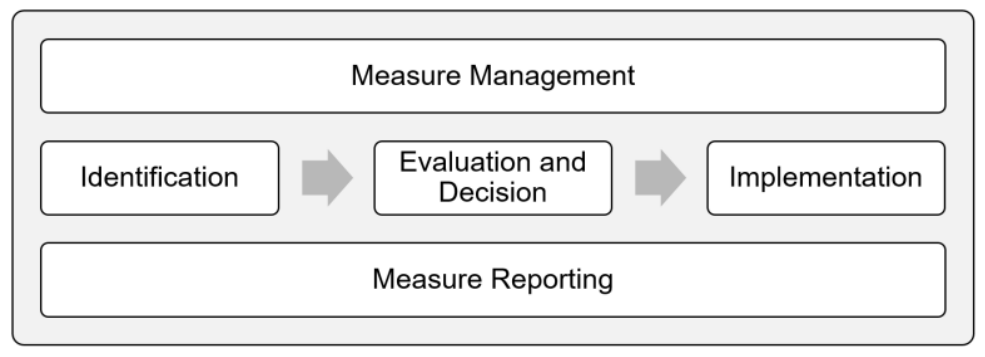

Figure 5. Approach to early product-cost optimization [38]

Though Figure 5 highlights an optimization measure's overall processual character, a measure's context still determines the emergence of (iterative) working steps to complete each process step within this approach. For instance, an optimization measure like make-or-buy decisions (Table 5) can only be evaluated and approved for implementation if all necessary information about sourcing alternatives is available. Depending on the product components a stakeholder wants to either make or buy; it is necessary to involve experts from different functional areas, e.g. purchasing or engineering (Figure 3), to work out and calculate costs for each and every sourcing alternative. This becomes even more complex within the discrete manufacturing industry, where supply chains for product components usually span multiple suppliers.

All in all, there is no doubt about the significance of early product-cost optimization and its potential for enterprises. Although information technology as well as product-costing methodologies have evolved (see Section 2), we highlighted a gap in the expedient utilization of such technologies in applied information technology. And even though the participating enterprises in the discrete manufacturing industry have a strong demand to overcome the current hurdles, their requirements evidently cannot be met by today's information systems.

\section{Conclusion}

In step with the evolution of the economic environment, product-costing has evolved to fit business requirements. As a result, cost optimization has shifted its focus from representing production-related optimization activities toward activities related to the early product cycle. Only by performing product-cost optimization during a product's development cycle can its immense potential for competitiveness be leveraged. Consequently, product-cost optimization has gained importance among discrete manufacturing industries. Here, we conducted interviews and expert sessions by joining two co-innovation workshops of SAP SE to gain a better understanding of and detailed insight into the process characteristics, deficits, and requirements related to support by information technology and information systems.

Early product-cost optimization goes along with different characteristics. Besides omnipresent information uncertainty about product designs or resources, there is strong pressure to fulfill internal and external demands. Generated information is used for decision-making at all 
organization levels, and, although enterprises rely heavily on cost estimates (e.g., to sign supply contracts for decades ahead), cost optimization suffers from rigid organizational structures that include many stakeholders. Therefore, it is surprising to find spreadsheet software such as Microsoft Excel as the tool of choice. Although this tool offers the necessary flexibility, it comes with several disadvantages that result in nontransparent, inconsistent, and inefficient processes, in turn causing negative impacts on enterprise profitability. Mainly, the status quo lacks integration with organizations' information-system landscapes, resulting in greater manual and error-prone efforts. As our research discovered, it is not only a question of domain-specific functionality being available on the market. Although software support is required, product costing uses and relies on expert knowledge. As soon as software provides cost calculations as a result of black-box processes, it starts to lose acceptance among the experts responsible for enterprise profitability. On those grounds, early product-cost optimization has strong potential to be supported by modern information technology. While the emphasis of past research was placed on different methodologies to estimate costs, today's IT support should be focused on realizing available potential by helping drive early cost-optimization processes. Thus, further research should analyze the most valuable improvements to draft concepts combining business requirements that consider the right degree of specification (see Section 5 and [38] for further details).

Overall, this article lays a foundation for our long-term research project based on design science research. It is important to highlight today's cost optimization problems within product development and the relevance of these problems for discrete manufacturing industries. It serves as a motivation to tackle these problems by iteratively constructing solutions following design science research process models [19]. This encompasses analyzing requirements in more detail based on the requirements outline provided in this article and designing and evaluating new artifacts to solve the problems uncovered in this article.

\section{References}

[1] I. Roda and M. Garetti, "TCO Evaluation in Physical Asset Management: Benefits and Limitations for Industrial Adoption," in Advances in Production Management Systems 2014, Proceedings, Part III, B. Grabot, B. Vallespir, S. Gomes, A. Bouras, and D. Kiritsis, Eds. Berlin: Springer, pp. 216-223, 2014. Available: https://doi.org/10.1007/978-3-662-44733-8_27

[2] A. Myrelid and J. Olhager, "Manufacturing Decision-Making Based on Product Costing and Management Accounting Information-a Critical Review," EIASM, 6th Conference on Performance Measurement and Management Control. Nice: European Institute for Advance Studies in Management, 2011.

[3] J.A. Brierly, "The Uses of Product Costs in Decision Making in British Manufacturing Industry," International Journal of Managerial and Financial Accounting, vol. 5, no. 3, pp. 294-309, 2013. Available: https://doi.org/10.1504/ijmfa.2013.058551

[4] R.S. Kaplan and S.R. Anderson, "Time-Driven Activity-Based Costing: A Simpler and More Powerful Path to Higher Profits,” Boston, MA: Harvard Business School Press, 2007.

[5] F. Öker and H. Adigüzel, "Time-Driven Activity-Based Costing: An Implementation in a Manufacturing Company," Journal of Corporate Accounting \& Finance, vol. 27, no. 3, pp. 39-56, 2016. Available: https://doi.org/10.1002/jcaf.22144

[6] K. Stouthuysen, K. Schierhout, F. Roodhooft, and E. Reusen, "Time-Driven Activity-Based Costing for Public Services," Public Money \& Management, vol. 34, no. 3, pp. 289-296, 2014. Available: https://doi.org/10.1080/09540962.2014.920202

[7] L. Siguenza-Guzman, A. Van den Abbeele, J. Vandewalle, H. Verhaaren, and D. Cattrysse, "Using TimeDriven Activity-Based Costing to Support Library Management Decisions: A Case Study for Lending and Returning Processes," The Library Quarterly, vol. 84, no. 1, pp. 76-98., 2014. Available: https://doi.org/10.1086/674032

[8] A. Andersch, U. Buehlmann, J. Palmer, J.K. Wiedenbeck, and S. Lawser, "Product Costing Guide for Wood Dimension and Component Manufacturers," Forest Products Journal, vol. 63, no. 7-8, pp. 247-256, 2013. Available: https://doi.org/10.13073/fpj-d-13-00060 
[9] S. Chayoukhi, Z. Bouaziz, and A. Zghal, "Costweld: A Cost Estimation System of Welding Based on the Feature Model," Advances in Production Engineering \& Management, vol. 4, pp. 263-274, 2009.

[10] J.G. Fisher and K. Krumwiede, "Product Costing Systems: Finding the Right Approach," Journal of Corporate Accounting \& Finance, vol. 26, no. 4, pp. 13-21, 2015. Available: https://doi.org/10.1002/jcaf.22045

[11] D. Lück, and C. Leyh, "Integrated Virtual Cooperation in Product Costing in the Discrete Manufacturing Industry: A Problem Identification," Proceedings of the Multikonferenz Wirtschaftsinformatik (MKWI 2016), pp. 279-290, 2016.

[12] D.R. Hansen and M.M. Mowen, Cornerstones of Cost Management, 2nd ed. Mason, OH: Cengage Learning, 2015.

[13] D.R. Hansen, M.M. Mown, and L. Guan, Cost Management: Accounting and Control, 6th ed. Mason, OH: Cengage Learning, 2009.

[14] S.L. Brown and K.M. Eisenhardt, "Product Development: Past Research, Present Findings, and Future Directions," Academy of Management Review, vol. 20, no. 2, pp. 343-378, 1995. Available: https://doi.org/10.5465/amr.1995.9507312922

[15] M. Walter and C. Leyh, "Knocking on Industry's Door: Product Cost Optimization in the Early Stages Requires Better Software Support," in 2017 IEEE 19th Conference on Business Informatics (CBI), pp. 330338, 2017.

[16] J. Stark, Product Lifecycle Management: 21st Century Paradigm for Product Realisation, 3rd ed. New York: Springer, 2015. Available: https://doi.org/10.1007/978-3-319-17440-2

[17] D. Lück and C. Leyh, "Toward Business Domain-Specific eCollaboration: Requirements for Integrated Virtual Cooperation in Product Costing," Proceedings of the 22nd Americas Conference on Information Systems (AMCIS 2016), 2016. Available: https://doi.org/10.1080/002075498193444

[18] A.R. Hevner, S.T. March, J. Park, and S. Ram, "Design Science in Information Systems Research," MIS Quarterly, vol. 28, no. 1, pp. 75-105, 2004. Available: https://doi.org/10.1007/978-3-319-17440-2_1

[19] K. Peffers, T. Tuunanen, C.E. Gengler, M. Rossi, W. Hui, V. Virtanen, and J. Bragge, “The Design Science Research Process: A Model for Producing and Presenting Information Systems Research" Proceedings of the 1st International Conference on Design Science in Information Systems and Technology (DESRIST), pp. 83106, 2006.

[20] R. Winter, "Design Science Research in Europe,” European Journal of Information Systems, vol. 17, pp. 470 475, 2008. Available: https://doi.org/10.2307/25148625

[21] H. Österle and B. Otto, “Consortium Research,” Business \& Information Systems Engineering, vol. 2, pp. 283293, 2010.

[22] H. Krasowski, "Life Cycle Engineering" in Environmental Management Accounting: Informational and Institutional Developments, M.D. Bennett, J.J. Bouma, and T.J. Wolters, Eds. New York: Springer, pp. 153157, 2002. Available: https://doi.org/10.1057/ejis.2008.44

[23] R.S. Kaplan and R. Cooper, Cost and Effect: Using Integrated Cost Systems to Drive Profitability and Performance, 3rd ed. Boston, MA: Harvard Business School Press, 1998.

[24] W. Männel, "Frühzeitige Produktkostenkalkulation für das Kostenmanagement” in Frühzeitiges Kostenmanagement: Kalkulationsmethoden und DV-Unterstützung, W. Männel, Ed.. Wiesbaden: Gabler Verlag, pp. 3-18, 1997. Available: https://doi.org/10.1007/978-3-322-84502-3_1

[25] T. Lucey, Management Accounting, 5th ed. London: Continuum International Publishing Group, 2003.

[26] R. Stibbe, Kostenmanagement: Methoden und Instrumente, 3rd ed. Munich: Oldenbourg Wissenschaftsverlag, 2009. Available: https://doi.org/10.1524/9783486849660

[27] G. Schicker, F. Mader, and F. Bodendorf, "Product Lifecycle Cost Management (PLCM): Status Quo, Trends und Entwicklungsperspektiven im PLCM-eine Empirische Studie," Arbeitspapier Wirtschaftsinformatik II (02/2008), Nürnberg: Universität Erlangen-Nürnberg, 2008.

[28] H.W. Stoll, Product Design Methods and Practices, New York, NY: CRC Press, 1999.

[29] A. Dimache, L. Dimache, E. Zoldi, and T. Roche, "Life Cycle Cost Estimation Tool for Decision-Making in the Early Phases of the Design Process" in Advances in Life Cycle Engineering for Sustainable Manufacturing Businesses-Proceedings of the 14th CIRP Conference on Life Cycle Engineering, S. Takata and Y. Umeda, Eds., pp. 455-459, 2007. Available: https://doi.org/10.1007/978-1-84628-935-4_79 
[30] M. Eigner and R. Stelzer, Product Lifecycle Management: Ein Leitfaden für Product Development und Life Cycle Management, 2nd ed. Heidelberg: Springer, 2009. Available: https://doi.org/10.1007/b93672

[31] P. Horváth, Controlling, 12th ed. Munich: Verlag Franz Vahlen, 2011. Available: https://doi.org/10.15358/9783800644551

[32] P.A. Nielsen and J.S. Persson, "Engaged Problem Formulation in IS Research," Communications of the Association for Information Systems, vol. $\quad 38, \quad$ pp. $\quad 720-737, \quad 2016$. Available: https://doi.org/10.17705/1CAIS.03835

[33] M. Rosemann and I. Vessey, "Toward Improving the Relevance of Information Systems Research to Practice: The Role of Applicability Checks," MIS Quarterly, vol. 32, no. 1, pp. 1-22, 2008. Available: https://doi.org/10.2307/25148826

[34] M. Mörtl and C. Schmied, "Design for Cost-A Review of Methods, Tools and Research Directions," Journal of the Indian Institute of Science, vol. 95, no. 4, pp. 379-404, 2015.

[35] Y. Asiedu and P. Gu, "Product Life Cycle Cost Analysis: State of the Art Review," International Journal of Production Research, vol. 36, no. 4, pp. 883-908, 1998. Available: https://doi.org/10.1080/002075498193444

[36] M.L. Markus, A. Majchrzak, and L. Gasser, “A Design Theory for Systems that Support Emergent Knowledge Processes," MIS Quarterly, vol. 26, no. 3, pp. 179-212, 2002.

[37] Z. Vosough, M. Walter, J. Rode, S. Hesse, and R. Groh, "Having Fun with Customers: Lessons Learned From an Agile Development of a Business Software," in Proceedings of 9th Nordic Conference on HumanComputer Interaction (NordiCHI'16). ACM, New York (2016).

[38] M. Walter, C. Leyh, and S. Strahringer, "Toward Early Product Cost Optimization: Requirements for an Integrated Measure Management Approach," Proceedings of the Multikonferenz Wirtschaftsinformatik (MKWI 2018), in press.

[39] T. Sasaki, "How the Japanese Accelerated New Car Development," Long Range Planning, vol. 24, no. 1, pp.15-25, 1991. Available: https://doi.org/10.1016/0024-6301(91)90020-O

[40] M.B. Clifton, W.P. Townsend, H.M. Bird, and R.E. Albano, Target Costing: Market-Driven Product Design, New York, NY: CRC Press, 2003.

[41] J.M. Daschbach and H. Apgar, "Design Analysis through Techniques of Parametric Cost Estimation," Engineering Costs and Production Economics, vol. 14, no. 2, pp. 87-93, 1988. Available: https://doi.org/10.1016/0167-188X(90)90111-T

[42] K.H. Chang, Product Manufacturing and Cost Estimating Using CAD/CAE: The Computer Aided Engineering Design Series, Oxford: Academic Press, 2013. Available: https://doi.org/10.1016/c2012-0-00833-2

[43] B.S. Dhillon, Life Cycle Costing: Techniques, Models and Applications, New York, NY: Gordon and Breach Science Publishers, 1989. Available: https://doi.org/10.4324/9780203823682

[44] K. Ehrlenspiel, A. Kiewert, and U. Lindemann, Cost-Efficient Design, M.S. Hundal, Ed., Berlin: Springer Berlin Heidelberg, 2007. Available: https://doi.org/10.1115/1.802507

[45] M. Böhringer, "Emergent Case Management for Ad-hoc Processes: A Solution Based on Microblogging and Activity Streams," in Business Process Management Workshops: BPM 2011, M. Zur Muehlen and J. Su, Eds. Heidelberg, $\quad$ Springer $\quad$ Berlin Heidelberg, $\quad$ pp. 2011. Available: https://doi.org/10.1007/978-3-642-20511-8_36 